\title{
MicroRNA-126 affects ovarian cancer cell differentiation and invasion by modulating expression of vascular endothelial growth factor
}

\author{
JIANQIAO LUO ${ }^{1,2}$, CAIDAN ZHU ${ }^{2}$, HONGYA WANG ${ }^{2}$, LI YU ${ }^{2}$ and JIANWEI ZHOU ${ }^{2}$ \\ ${ }^{1}$ Department of Gynecology, Shaoxing Shangyu Women and Children Hospital, Shaoxing, Zhejiang 312000; \\ ${ }^{2}$ Department of Gynecology, The Second Affiliated Hospital, School of Medicine, \\ Zhejiang University, Hangzhou, Zhejiang 310009, P.R. China
}

Received April 17, 2016; Accepted November 2, 2017

DOI: $10.3892 / \mathrm{ol} .2018 .8025$

\begin{abstract}
Primary ovarian cancer is the main cause of gynecological cancer-associated mortality. However, the mechanism behind the spread of ovarian cancer requires elucidation. The present study aimed to investigate the effects of microRNA-126 (miR-126) on differentiation and invasion, and its mechanism in primary ovarian cancer. Ovarian cancer SKOV3 cells transfected with LV3-has-miR-126 mimics and LV3-has-miR-126 inhibitor were produced; it was revealedthatLV-miR-126 mimics could induce cell cycle arrest at $G_{1}$ phase, suppress cell invasion through Matrigel-coated membranes and downregulate the expression of vascular endothelial growth factor (VEGF). Furthermore, LV-has-miR-126 inhibitor-transfected cells could increase the number of cells in $\mathrm{S}$ phase, induce cell invasion and upregulate the expression of VEGF. The present study, to the best of our knowledge, is the first to report that miR-126 may serve tumor suppressor roles by inducing $\mathrm{G}_{1}$ cell cycle arrest and suppressing invasion in ovarian cancer cells, at least in part by targeting VEGF expression.
\end{abstract}

\section{Introduction}

Primary ovarian cancer is the leading cause of gynecological cancer-associated mortality cause of death in patients with and most cases are diagnosed at an advanced stage with lymph node metastasis (1-3). Overall 5-year survival rates of patients with advanced ovarian cancer undergoing comprehensive surgical procedures remain low, owing to the spread of ovarian cancer cells throughout the peritoneal cavity (4). The majority of women are diagnosed with stage III or IV cancer $(5,6)$.

Correspondence to: Dr Jianwei Zhou, Department of Gynecology, The Second Affiliated Hospital, School of Medicine, Zhejiang University, 9 Jiefang Road, Hangzhou, Zhejiang 310009, P.R. China E-mail: zhou_jianwei@126.com; 2195045@zju.edu.cn

Key words: microRNA-126, vascular endothelial growth factor, ovarian cancer, cell cycle, invasion
Vascular endothelial growth factor (VEGF) is a potent mediator of angiogenesis that induces the formation of novel blood vessels, and the growth and metastasis of cancers $(7,8)$. The growth and spread of tumors depends on the formation of an adequate vascular support and amoeboid mode of tumor cell invasion (9). Furthermore, several studies have indicated that VEGF serves a role in promoting endothelial cell proliferation and migration, and induces a direct effect on cell proliferation and invasiveness $(3,10,11)$. Previous studies have indicated that suppressing the expression or activity VEGF in ovarian cancer cells may represent a potential anticancer therapy (12-14).

MicroRNAs (miRNAs/miRs) are 22-nucleotide-long non-coding RNAs that regulate the expression of target mRNAs and are involved in cellular processes, including proliferation, differentiation, apoptosis and development (15-17). miR-126 is upregulated in the endothelium and originates from a common precursor structure located within the epidermal growth factor-like protein 7 gene $(18,19)$. Several online databases are available to identify potential miRNA targets. Analysis preformed using the PicTar algorithm (http://www.pictar.org/) (20), miRBase (www.mirbase.org) (21) and TargetScan target prediction (version 6.2; www.targetscan.org) (22) tools revealed that VEGF was the putative target of miR-126 that may serve a role in angiogenesis owing to regulation of VEGF signaling $(23,24)$. Alteration of expression of miR-126 was also reported in various breast, lung and prostate cancer cells (24-26). However, the cellular mechanisms underlying the effect of miR-126 on ovarian cancer cells remains to be elucidated.

The present study aimed to characterize the role of miR-126, and the signaling pathway that it may be involved in, in the pathogenesis of ovarian cancer cells. Using SKOV3 ovarian cancer cells with up or downregulated miR-126, the present study attempted to identify the role of miR-126 in ovarian cancer cells.

\section{Materials and methods}

Cell culture. The ovarian cancer SKOV3 cell line (American Type Culture Collection, Manassas, VA, USA) was used in the present study. Cells were maintained and propagated in vitro by 
serial passage in Dulbecco's modified Eagle's medium (DMEM; Gibco; Thermo Fisher Scientific, Inc., Waltham, MA, USA) supplemented with $10 \%$ fetal bovine serum (FBS; Gibco; Thermo Fisher Scientific, Inc.), $100 \mathrm{IU} / \mathrm{ml}$ penicillin and $100 \mu \mathrm{g} / \mathrm{ml}$ streptomycin (Sigma-Aldrich; Merck KGaA, Darmstadt, Germany) in a humidified environment in $5 \% \mathrm{CO}_{2}$ at $37^{\circ} \mathrm{C}$.

Plasmid construction, lentivirus package and cell infection. The lentiviral vector pGLV3/H1/GFP+Puro (pGLV3; Shanghai GenePharma Co., Ltd., Shanghai, China) was used to construct the pGLV3-miR-126 plasmid. miR-126 mimics, miR-126 inhibitor and negative control (NC) oligonucleotides were synthesized by Shanghai GenePharma Co., Ltd. The following sequences were used: miR-126, 5'-TCGTACCGTGAGTAATAATGCG-3'; hsa-miR-126 inhibitor, 5'-CGCATTATTACTCACGGTACGA-3'; and miR-NC, 5'-TTCTCCGAACGTGTCACGT-3'. miR-126 shDNA double chain template sequence was synthesized artificially and cloned into pGLV3-miRNA lentivirus plasmid. The miR-126 mimic sequence was chemosynthesized by Shanghai GenePhama Co., Ltd. using the following primers: hsa-miR-126-BamHI forward, 5'-GATCCGTCGTACCGTGAG TAATAATGCGTTCAAGAGACGCATTATTACTCACGGTA CGACTTTTTTG-3' and hsa-miR-126-EcoRI reverse, 5'-AAT TCAAAAAAGTCGTACCGTGAGTAATAATGCGTCTCTT GAACGCATTAT TACTCACGGTACGACG-3'. The miRNA-126 inhibitor sequence was synthesized using the following primers: hsa-miR-126-BamHI forward, 5'-GATC CGAGCATGGCACTCATTATTACGCTTCAAGAGAGCGT AATAATGAGTGCCATGCTCTTTTTTG-3' and hsamiR-126-EcoRI reverse, 5'-AATTCAAAAAAGAGCATGGCA CATGCTCG-3'. The NC was pGLV3-shDNA-NC and the following sequence was used: NC-BamHI forward, 5'-GATCC GTCGTACCGTGAGTAATAATGCGTTCAAGAGACGCATT ATTACTCACGGTACGACTTTTTTG-3' and shNC-EcoRI reverse, 5'-AATTCAAAAAAGTCGTACCGTGAGTAATAAT GCGTCTCTTGAACGCATTATTACTCACGGTACGACG-3'. All the sequences of resulting vectors were verified with sequence analysis by Shanghai GenePhama Co., Ltd.

The 293T cell line (Type Culture Collection of the Chinese Academy of Sciences, Shanghai, China) was maintained in DMEM, 10\% FBS, 4.0 mM L-glutamine, $100 \mathrm{U} / \mathrm{ml}$ penicillin and $100 \mu \mathrm{g} / \mathrm{ml}$ streptomycin (Sigma-Aldrich; Merck KGaA) at $37^{\circ} \mathrm{C}$ and $95 \% \mathrm{CO}_{2}$ in order to produce lentivirus packing plasmids. At 1 day prior to transfection, $5 \times 10^{6}$ cells were seeded into a $15-\mathrm{cm}$ dish. pGLV3-miR-126 or pGLV3 vector and packing plasmids, including $\mathrm{pGag} / \mathrm{Pol}$, pRev and pVSV-G were co-transfected using RNAi-mate transfection reagent (both from Shanghai GenePharma Co., Ltd.), according to the manufacturer's protocol. A total of $72 \mathrm{~h}$ following transfection, the supernatant was collected and centrifuged at 8,500 $\mathrm{x} \mathrm{g}$ at $4^{\circ} \mathrm{C}$ for $4 \mathrm{~min}$, and passed through a $0.45-\mu \mathrm{m}$ syringe filter. Subsequently, the sample was centrifuged again at 48,400 x g at $4^{\circ} \mathrm{C}$ for $2 \mathrm{~h}$. The viral titer of miR-126 mimic, miR-126 inhibitor and the negative control was measured according to the expression level of green fluorescent protein (GFP) according to the manufacturer's protocol (Shanghai GenePhama Co. Ltd.). Packaged lentiviruses were named LV3-has-miR-126, LV3-has-miR-126 inhibitor and LV3-NC. All sequences of resulting vectors were verified with sequence analysis by Shanghai GenePhama Co., Ltd.
SKOV3 cells were infected with LV3-has-miR-126, LV3-has-miR-126 inhibitor and LV3-NC as LV3-has-miR-126 mimic group, LV3-has-miR-126 inhibitor group and NC group respectively, while uninfected SKOV3 cells were the untreated SKOV3 cells group. The SKOV3 cells of the first three groups were infected at a multiplicity of infection (MOI) of 15 in the presence of $5 \mu \mathrm{g} / \mathrm{ml}$ polybrene (Shanghai GenePharma Co., Ltd.). Efficiency of infection was $\sim 90 \%$ as assessed by GFP and fluorescent microscopy. Cells were used for subsequent experimentation $72 \mathrm{~h}$ after transfection.

Cell cycle assay. Cells from all treatment groups were harvested at $48 \mathrm{~h}$ following transfection, fixed in $70 \%$ ice-cold ethanol overnight at $0^{\circ} \mathrm{C}$ and washed with $1 \mathrm{X}$ Buffer A (centrifugation at $4,200 \mathrm{x} \mathrm{g}$ for $5 \mathrm{~min}$ at $0^{\circ} \mathrm{C}$ ). Subsequently, $5 \mu 1$ propidium iodide (Nanjing KeyGen Biotech Co., Ltd., Nanjing, China) was added into $0.5 \mathrm{ml}$ of cell suspension $\left(5 \times 10^{5}\right.$ cells) for $15 \mathrm{~min}$ at room temperature. Experiments were performed in triplicate for each sample and analyses were performed using a flow cytometer (FACSCanto II; BD Biosciences, Franklin Lakes, NJ, USA) in accordance with the manufacturer's protocol. Multicycle software for Windows (Phoenix Flow Systems, San Diego, CA, USA) was used to determine the percentage of cells in $\mathrm{G}_{1}, \mathrm{G}_{2}$ and $\mathrm{S}$ stages.

Cell invasion assay. A total of $48 \mathrm{~h}$ following transfection, the invasive ability of cells was assayed using a Transwell invasion assay (8-mm pore size). Transwell inserts were put into the 24-well plates. A total of $0.1 \mathrm{ml} \mathrm{Matrigel}(50 \mathrm{mg} / \mathrm{ml}$; BD Biosciences) was added onto the plate surface and incubated for $4-5$ h. SKOV3 cells were freshly trypsinized $(0.25 \%$ trypsin) at $37^{\circ} \mathrm{C}$ for $3 \mathrm{~min}$ and washed with PBS, then suspended in DMEM with $0.1 \%$ BSA (Gibco; Thermo Fisher Scientific, Inc.). Subsequently, $0.1 \mathrm{ml}$ cell suspension $\left(1 \times 10^{5}\right.$ cells $)$ was added to the upper chamber of each insert coated with Matrigel. A total of $0.5 \mathrm{ml}$ DMEM containing 20\% FBS was added into the lower chamber and cells were allowed to invade for $24 \mathrm{~h}$ at $37^{\circ} \mathrm{C}$ in a $5 \% \mathrm{CO}_{2}$ humidified incubator. Following the incubation, cells on the membrane were removed using a cotton swab and $0.05 \%$ crystal violet stain was used to identify migratory cells at $20^{\circ} \mathrm{C}$ for $30 \mathrm{~min}$ The number of migratory cells on the lower surface of the membrane was counted under Nikon Labophot 2 light microscope (Nikon Corp., Tokyo, Japan; 10 fields of vision) at a magnification of $\mathrm{x} 200$.

Immunofluorescencestainingandwesternblotanalysis. Analysis preformed using the PicTar algorithm (http://www.pictar. org/) (20), miRBase (www.mirbase.org) (21) and TargetScan target prediction (version 6.2; www.targetscan.org) (22) tools revealed that VEGF was the putative target of miR-126. Therefore, the expression of VEGF was explored in all groups. A total of $48 \mathrm{~h}$ after transfection, cells were fixed in $4 \%$ paraformaldehyde for $30 \mathrm{~min}$ at $20^{\circ} \mathrm{C}$, washed three times with PBS, and incubated for $5 \mathrm{~min}$ at $-20^{\circ} \mathrm{C}$ in $95 \%$ ethanol (v/v in PBS). Cells were subsequently washed three times with PBS, blocked for $1 \mathrm{~h}$ at $20^{\circ} \mathrm{C}$ in $5 \%$ normal goat serum (Wuhan Boster Biological Technology, Ltd., Wuhan, China) in PBS with $0.1 \%$ Triton X-100 and incubated overnight with anti-VEGF antibodies (cat no. BA0407; 1:200; Wuhan Boster Biological Technology, Ltd.) at $4^{\circ} \mathrm{C}$. Cells were subsequently 
washed three times with PBS and incubated for $40 \mathrm{~min}$ at $37^{\circ} \mathrm{C}$ with the corresponding secondary antibody (goat anti-rabbit immunoglobulin $(\mathrm{Ig}) \mathrm{G}(\mathrm{H}+\mathrm{L})$-tetramethylrhodamine (TRITC; cat no. BA1090; 1:100; Wuhan Boster Biological Technology, Ltd.). Cells were washed with PBS and mounted onto the glass slides. Immunostained SKOV3 cultures were examined under a Zeiss laser scanning confocal microscope at a magnification of x200 (LSM 510 META; Carl Zeiss AG, Oberkochen, Germany) for detection of the TRITC fluorophore by semi-quantitative confocal laser scanning analysis-Image-Pro Plus 6.0 (Media Cybernetics, Inc., Rockville, MD USA).

For western blot analysis, proteins were extracted from SKOV3 cells. Proteins were solubilized in Radioimmunoprecipitation assay buffer (Sangon Biotech Co., Ltd., Shanghai, China) and proteins quantified using the BCA Protein Assay kit (Beyotime Institute of Biotechnology, Haimen, China) were separated at $30 \mu \mathrm{g}$ per lane on $10 \%$ SDS-PAGE and electro-transferred onto polyvinylidene difluoridemembrane. The membrane was blocked in 5\% skimmed milk powder prepared in Tris-buffered saline with 0.1\% Tween-20 (TBS-T; Sangon Biotech Co., Ltd.) for $30 \mathrm{~min}$ at $20^{\circ} \mathrm{C}$. For VEGF detection, membranes were incubated at $4^{\circ} \mathrm{C}$ overnight with anti-VEGF antibodies (cat no. BA0407; 1:500; Wuhan Boster Biological Technology, Ltd.) and anti- $\beta$-actin antibodies (cat no. BM0627; 1:200; Wuhan Boster Biological Technology, Ltd.). Membranes were washed 3 times for $10 \mathrm{~min}$ in TBS-T and incubated with a 1:5,000 dilution of horseradish peroxidase-conjugated goat anti-rabbit IgG (cat no. BA1054; Wuhan Boster Biological Technology, Ltd.) for $2 \mathrm{~h}$. Membranes were washed 6 times for $20 \mathrm{~min}$ with TBS-T prior to development with a standard enhanced chemiluminescence kit (ECL kit; Nanjing KeyGen Biotech Co., Ltd., Nanjing, China). Densitometry analysis of the bands was performed using Quantity One software (version 4.6; Bio-Rad Laboratories, Inc., Hercules, CA, USA).

Statistical analysis. Data are presented as the mean \pm standard deviation $(n=5)$. Statistical analysis was performed using SPSS software (version 14.0; IBM Corp., Armonk, NY, USA ). The significance of any differences was evaluated using one-way analysis of variance followed by a Tukey post-hoc test. $\mathrm{P}<0.05$ was considered to indicate a statistically significant difference.

\section{Results}

Cell cycle assay. Cell cycle analysis was used to determine whether the effect of miR-126 on proliferation of SKOV3 cells was due to cell cycle alterations. The results demonstrated that the percentage of cells in $G_{1}$ phase increased to $54.65 \%$, whereas the percentage of cells in $\mathrm{S}$ phase decreased to $34.44 \%$ in the miR-126 mimic group compared with the NC group $\left(\mathrm{G}_{1}\right.$ phase, $44.47 \%$ and $\mathrm{S}$ phase, $53.12 \%$ in the $\mathrm{NC}$ group). The percentage of cells in $\mathrm{G}_{2}$ phase was $2.41 \%$ in the NC group and $10.90 \%$ in the miR-126 mimic group $(\mathrm{P}<0.05)$. These results indicate that the overexpression of miR-126 in SKOV3 cells induced $\mathrm{G}_{1}$ cell cycle arrest. Cell cycle analysis was also conducted in the miR-126 inhibitor group. Following transduction with the LV3-miR-126 inhibitor for $48 \mathrm{~h}$, flow cytometry analysis revealed that SKOV3 cells were promoted from the $G_{1}$ phase into the $S$ phase. The percentage of cells in $\mathrm{G}_{1}$ phase was from $44.47 \%$ in the $\mathrm{NC}$ group and $9.42 \%$ in the miR-126 inhibitor group, while the percentage of cells in $\mathrm{S}$ phase was $53.12 \%$ in the NC group and $90.58 \%$ in the miR-126 inhibitor group $(\mathrm{P}<0.05)$. There were no significant alterations in cell cycle ratios between the untreated group and the NC group ( $\mathrm{P}>0.05$; Fig. 1). The results demonstrated that miR-126 mimic arrested SKOV3 cells at the $G_{1}$ phase while the miR-126 inhibitor induced cell cycle progression.

Cell invasion assay. The number of SKOV3 cells in the miR-126 mimic group that invaded through the Matrigel-coated membranes was significantly lower than that in the untreated group ( $164.6 \pm 25.8$ vs. $253.1 \pm 14.9$ cells, respectively; $\mathrm{P}<0.05$; Fig. 2). Furthermore, the depletion of miR-126 significantly promoted SKOV3 cell invasion through Matrigel-coated membranes, compared with the untreated group (290.9 \pm 13.2 cells vs. $253.1 \pm 14.9$ cells, respectively; $\mathrm{P}<0.05$; Fig. 2 ). There were no significant differences between the number of invaded NC cells and that of the untreated cells $(256.5 \pm 15.2$ vs. $253.1 \pm 14.9$ cells respectively; $\mathrm{P}>0.05$; Fig. 2). These results indicated that downregulation of miR-126 may promote cell invasion, whereas upregulation of miR-126 inhibits the invasion of cells through Matrigel-coated membranes.

Immunofluorescence staining and western blot analysis. Immunofluorescence double staining and semi-quantitative confocal laser scanning analysis revealed that miRNA vectors and VEGF were expressed in the four treatment groups. Green fluorescence, indicating vector-transfected cells, was detected in all cell nuclei and only certain cytoplasmic areas. The red fluorescence detected in the cytoplasm of SKOV3 cells indicated VEGF expression. The results of immunofluorescence staining demonstrated that transfection with miR-126 mimics mediated the inhibition of VEGF expression. The mean immunofluorescence intensity of VEGF in the miR-126 inhibitor group was significantly increased compared with that in the control group ( $\mathrm{P}<0.05$; Fig. 3). Furthermore, the expression level of VEGF decreased as a result of overexpression of miR-126 in LV3-has-miR-126-transfected SKOV3 cells, compared with untreated and negative control cells (Fig. 3). These results further indicated that miR-126 has an inhibitory role on VEGF expression in SKOV3 cells.

VEGF protein was detected in all treatment groups as a single band at $28 \mathrm{kDa}$. Densitometry analysis of the VEGF bands revealed a significant increase in expression levels $(110.4 \pm 6.8 \%)$ in the LV3-has-miR-126 inhibitor group and a significant decrease $(31.2 \pm 2.2 \%)$ in the LV3-has-miR-126 mimic group, compared with the untreated group $(71.4 \pm 2.8 \%$; both $\mathrm{P}<0.05$; Fig. 4). There was no significant difference between the NC control group and the untreated group (70.9 \pm 3.8 vs. $71.4 \pm 2.8 \%$, respectively; P>0.05; Fig. 4 ). The above results indicate that VEGF was upregulated in SKOV3 cells transfected with LV3-has-miR-126 inhibitor, whereas VEGF expression was inhibited following LV3-has-miR-126 mimic transfection.

\section{Discussion}

miR-126 has been reported to be downregulated in human breast, lung, stomach, cervix and pancreas cancer (24,27-30). Furthermore, patients with non-small cell lung cancer and 

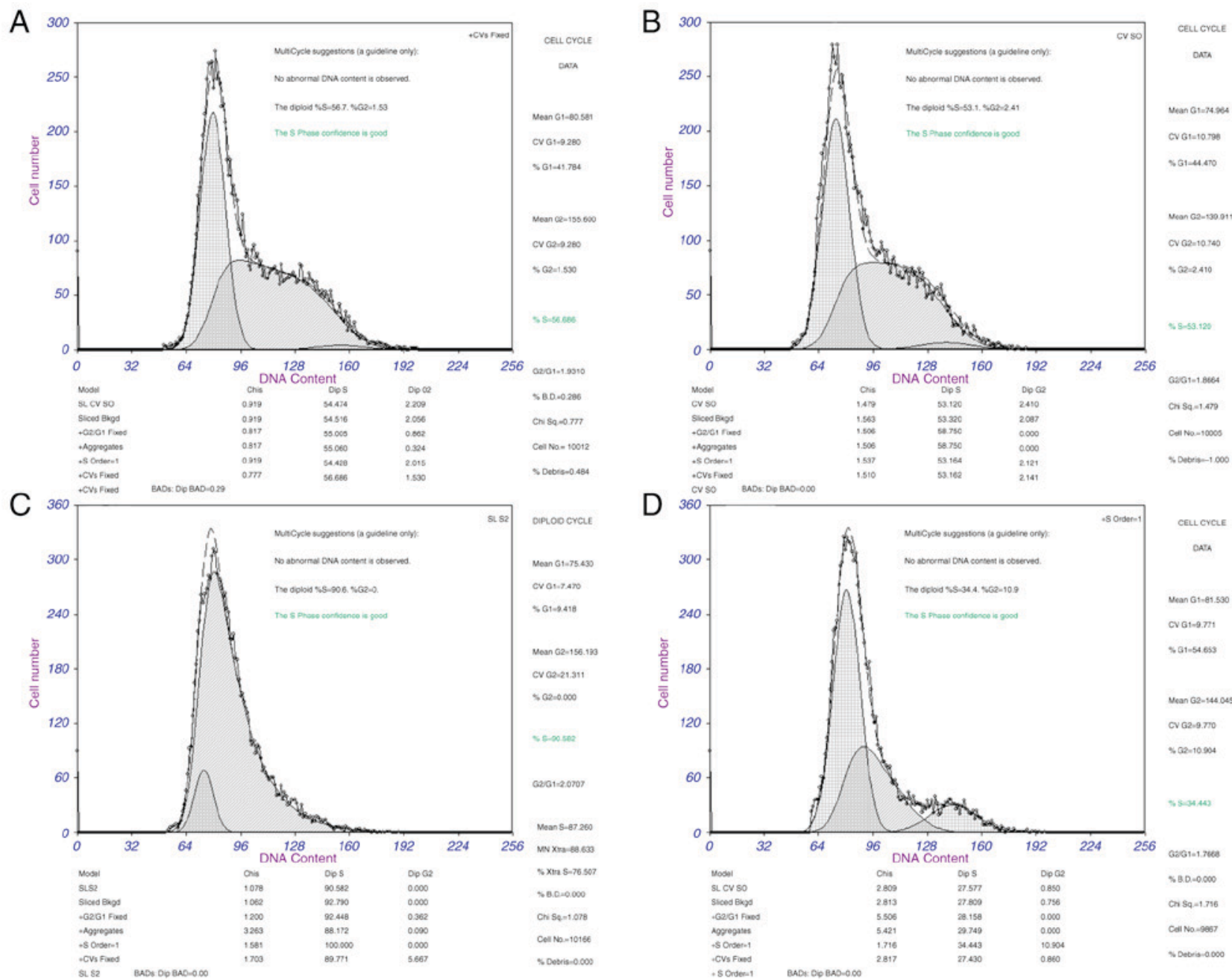

Figure 1. SKOV3 cell cycle analysis detected by flow cytometry. (A) Untreated SKOV3 cells. (B) SKOV3 cells transfected with LV3 negative control. (C) SKOV3 cells transfected by LV3-has-miR-126 inhibitor. (D) SKOV3 cells transfected by LV3-has-miR-126.

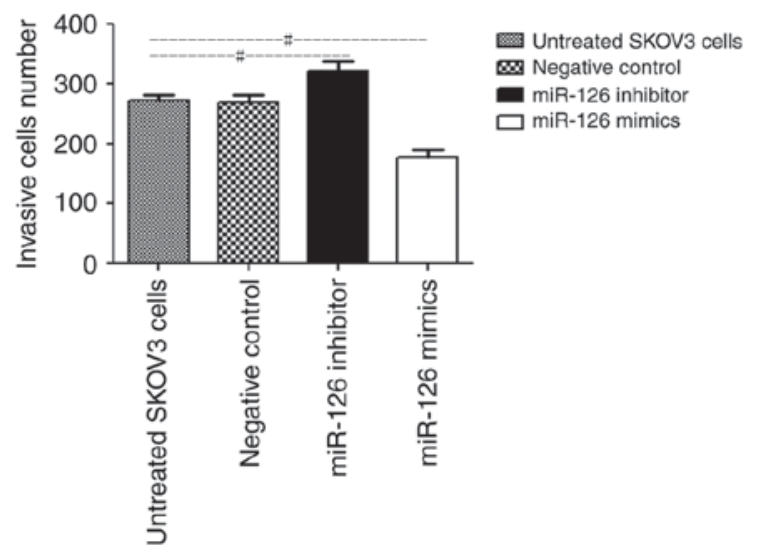

Figure 2. Number of invasive cells in the untreated SKOV3 group, SKOV3 cells transfected with LV3 negative control, SKOV3 cells transfected with LV3-has-miR-126 inhibitor and SKOV3 cells transfected with LV3-has-miR-126. Data are presented as mean \pm standard deviation. ${ }^{*} \mathrm{P}<0.05$ with comparisons shown by lines. miR, microRNA.

primary breast tumors exhibiting low miR-126 expression displayed poor survival compared with patients with high miR-126 levels (25). These studies indicated the presence of an association between the expression of miR-126 and metastasis-free survival. The present study demonstrated that ovarian cancer cells transfected with miR-126 exhibited a significantly increased frequency of cells in $\mathrm{G}_{1}$ phase and a lower frequency of cells in $\mathrm{S}$ phase. The percentage of cells in $G_{1}$ phase in the miR-126 mimic group was markedly higher than that in the NC group. These results demonstrated that miR-126 could induce ovarian cancer cell cycle arrest, whereas inhibition miR-126 promoted cell cycle progression and induced ovarian tumor cell proliferation.

Previous studies demonstrated that VEGF serves a role in the modulation of cellular functions, including angiogenesis, tumor cell proliferation and invasiveness (31-33). VEGF increases vascular permeability and leads to malignant ascites in later stages of ovarian cancer, indicating disease progression and treatment failure $(31,34)$. Therefore, anti-VEGF treatment could aid in improving patient survival (35). Clinical trials have demonstrated that certain anti-VEGF agents, including bevacizumab, can increase the risk of treatment-associated death caused by pulmonary hemorrhage, hypertension, proteinuria or bleeding, owing to disruption of normal vasculature $(36,37)$. These side effects limit the therapeutic usage of anti-VEGF agents. The targeting of endogenous miRNAs provides an alternative approach to anti-VEGF treatment (38). Online accessible algorithms, including PicTar, miRBase and TargetScan, 

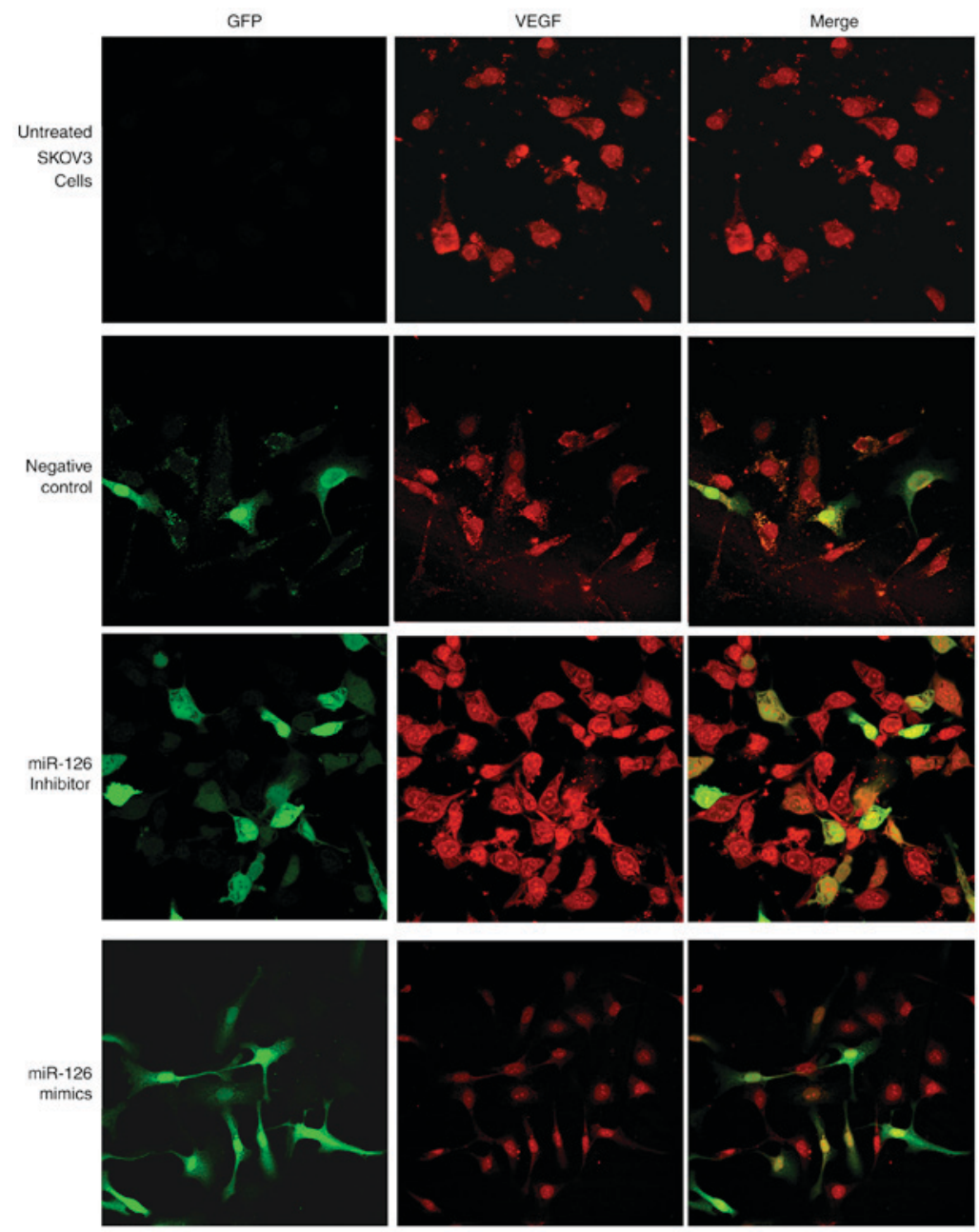

Figure 3. Immunofluorescence staining demonstrated suppression of VEGF by miR-126 in transfected cells. Cells were grown on coverslips overnight and subsequently subjected to immunostaining with anti-VEGF antibody. VEGF-positive cells were stained red, whereas GFP-positive cells were stained green. Merged images present VEGF and GFP. miR-126, microRNA-126; VEGF, vascular endothelial growth factor; GFP, green fluorescent protein.
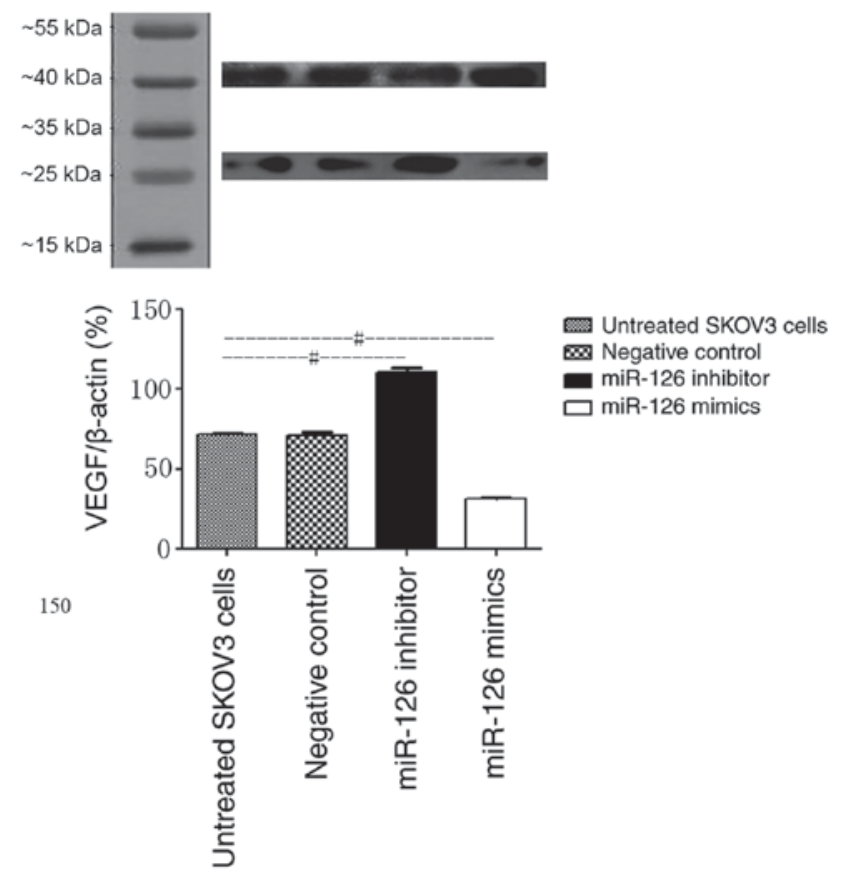

Figure 4. Western blot analysis of cells in all groups. Data are presented as the mean \pm standard deviation. ${ }^{~} \mathrm{P}<0.05$ with comparisons shown by lines. miR-126, microRNA-126; VEGF, vascular endothelial growth factor. demonstrated that one of the potential targets of miR-126 is VEGF $(18,19)$. The present study demonstrated that miR-126 was a target of VEGF and the upregulation of miR-126 markedly inhibited VEGF expression. The present study aimed to elucidate the interaction between miR-126 and VEGF in ovarian cancer cells. The results demonstrated that SKOV3 cells infected with LV-miR-126 can efficiently reduce the expression of VEGF. Furthermore, SKOV3 cells infected with LV-miR-126 inhibitor exhibited overexpression of VEGF and the cell proliferation as $90.58 \%$ cells of S phase vs. $53.12 \%$ in the NC group.

Invasion through the basement membrane is one of the features of aggressive tumors (39); therefore, the present study further investigated the association between the expression of miR-126 and ovarian cell invasion. Cells transfected with LV-has-miR-126 inhibitor exhibited increased invasiveness compared with the untreated group. The results also demonstrated that increasing the expression of miR-126 in ovarian cancer cells could reduce the invasiveness. We hypothesize that low expression of miR-126 promotes VEGF expression and cell invasion, leading to the development of ovarian cancer.

In conclusion, to the best of our knowledge, the present study is the first to present data indicating that miR-126 is a tumor suppressor that can induce ovarian cancer cell cycle arrest and suppress invasion, at least in part, by targeting VEGF 
expression. miR-126 may be used as a potential marker for clinical prognosis and treatment of ovarian cancer in the future.

\section{Acknowledgements}

The present study was supported by the Natural Science Foundation of Zhejiang Province (grant no. LY13H160018) and the National Natural Science Foundation of China (grant no. 81371881). The authors would like to thank Dr Faisal Rehman (Zhejiang University, Zhejiang, China) for critical proofreading of the manuscript and language correction.

\section{Competing interests}

The authors declare that they have no competing interests.

\section{References}

1. Bertone-Johnson ER: Epidemiology of ovarian cancer: A status report. Lancet 365: 101-102, 2005.

2. Smolle E, Taucher V and Haybaeck J: Malignant ascites in ovarian cancer and the role of targeted therapeutics. Anticancer Res 34: 1553-1561, 2014.

3. Sun L, Li L, Li Z, Hong S, Yang Q, Qu X and Kong B: Alterations in the serum proteome profile during the development of ovarian cancer. Int J Oncol 45: 2495-2501, 2014.

4. Matsuda A and Katanoda K: Five-year relative survival rate of ovarian cancer in the USA, Europe and Japan. Jpn J Clin Oncol 44: 196, 2014.

5. Ovarian cancer, five-year stage-specific relative survival rates (2004-2008). J Natl Cancer Inst 103: 1287, 2011.

6. Mury D, Woelber L, Jung S, Eulenburg C, Choschzick M, Witzel I, Schwarz J, Jaenicke F and Mahner S: Prognostic and predictive relevance of CA-125 at primary surgery of ovarian cancer. J Cancer Res Clin Oncol 137: 1131-1137, 2011.

7. Patterson DM, Gao D, Trahan DN, Johnson BA, Ludwig A, Barbieri E, Chen Z, Diaz-Miron J, Vassilev L, Shohet JM and Kim ES: Effect of MDM2 and vascular endothelial growth factor inhibition on tumor angiogenesis and metastasis in neuroblastoma. Angiogenesis 14: 255-266, 2011.

8. Bieri M, Oroszlan M, Farkas A, Ligeti N, Bieri J and Mohacsi P: Anti-HLA I antibodies induce VEGF production by endothelial cells, which increases proliferation and paracellular permeability. Int J Biochem Cell Biol 41: 2422-2430, 2009.

9. Qiao L, Liang N, Zhang J, Xie J, Liu F, Xu D, Yu X and Tian Y: Advanced research on vasculogenic mimicry in cancer. J Cell Mol Med 19: 315-326, 2015.

10. Awazu Y, Mizutani A, Nagase Y, Tsuchiya S, Nakamura K, Kakoi Y, Kitahara O, Takeuchi T, Yamasaki S, Miyamoto N, et al: Anti-angiogenic and anti-tumor effects of TAK-593, a potent and selective inhibitor of vascular endothelial growth factor and platelet-derived growth factor receptor tyrosine kinase. Cancer Sci 104: 486-494, 2013.

11. Hu P, Liu W, Wang L, Yang M and Du J: High circulating VEGF level predicts poor overall survival in lung cancer. J Cancer Res Clin Oncol 139: 1157-1167, 2013.

12. Rinck-Junior JA, Oliveira C, Lourenço GJ, Sagarra RA, Derchain SF, Segalla JG and Lima CS: Vascular endothelia growth factor (VEGF) polymorphism and increased risk of epithelial ovarian cancer. J Cancer Res Clin Oncol 141: 69-73, 2015.

13. Kim KK, Singh AP, Singh RK, Demartino A, Brard L, Vorsa N, Lange TS and Moore RG: Anti-angiogenic activity of cranberry proanthocyanidins and cytotoxic properties in ovarian cancer cells. Int J Oncol 40: 227-235, 2012.

14. He Z, Li B, Rankin GO, Rojanasakul Y and Chen YC: Selecting bioactive phenolic compounds as potential agents to inhibit proliferation and VEGF expression in human ovarian cancer cells. Oncol Lett 9: 1444-1450, 2015.

15. Nikitina EG, Urazova LN and Stegny VN: MicroRNAs and human cancer. Exp Oncol 34: 2-8, 2012.

16. Zheng X, Dong J, Gong T, Zhang Z, Wang Y, Li Y, Shang Y, Li K, Ren G, Feng B, et al: MicroRNA library-based functional screening identified miR-137 as a suppresser of gastric cancer cell proliferation. J Cancer Res Clin Oncol 141: 785-795, 2015.
17. Luo P, Fei J, Zhou J and Zhang W: microRNA-126 suppresses PAK4 expression in ovarian cancer SKOV3 cells. Oncol Lett 9: 2225-2229, 2015.

18. Kuhnert F, Mancuso MR, Hampton J, Stankunas K, Asano T, Chen CZ and Kuo CJ: Attribution of vascular phenotypes of the murine Egfl7 locus to the microRNA miR-126. Development 135: 3989-3993, 2008.

19. Zhang Y, Yang P, Sun T, Li D, Xu X, Rui Y, Li C, Chong M, Ibrahim T, Mercatali L, et al: miR-126 and miR-126* repress recruitment of mesenchymal stem cells and inflammatory monocytes to inhibit breast cancer metastasis. Nat Cell Biol 15: 284-294, 2013.

20. Krek A, Grün D, Poy MN, Wolf R, Rosenberg L, Epstein EJ, MacMenamin P, da Piedade I, Gunsalus KC, Stoffel M, et al: Combinatorial microRNA target predictions. Nat Genet 37: 495-500, 2005.

21. Kozomara A and Griffiths-Jones S: miRBase: Annotating high confidence microRNAs using deep sequencing data. Nucleic Acids Res 42: D68-D73, 2014.

22. Lewis BP, Burge CB and Bartel DP: Conserved seed pairing, often flanked by adenosines, indicates that thousands of human genes are microRNA targets. Cell 120: 15-20, 2005.

23. Sasahira T, Kurihara M, Bhawal UK, Ueda N, Shimomoto T, Yamamoto K, Kirita T and Kuniyasu H: Downregulation of miR-126 induces angiogenesis and lymphangiogenesis by activation of VEGF-A in oral cancer. Br J Cancer 107: 700-706, 2012.

24. Zhu N, Zhang D, Xie H, Zhou Z, Chen H, Hu T, Bai Y, Shen Y, Yuan W, Jing Q and Qin Y: Endothelial-specific intron-derived miR-126 is down-regulated in human breast cancer and targets both VEGFA and PIK3R2. Mol Cell Biochem 351: 157-164, 2011.

25. Jusufović E, Rijavec M, Keser D, Korošec P, Sodja E, Iljazović E, Radojević $Z$ and Košnik M: Let-7b and miR-126 are down-regulated in tumor tissue and correlate with microvessel density and survival outcomes in non-small-cell lung cancer. PLoS One 7: e45577, 2012.

26. Musiyenko A, Bitko V and Barik S: Ectopic expression of miR-126*, an intronic product of the vascular endothelial EGF-like 7 gene, regulates prostein translation and invasiveness of prostate cancer LNCaP cells. J Mol Med (Berl) 86: 313-322, 2008.

27. Miko E, Margitai Z, Czimmerer Z, Várkonyi I, Dezso B, Lányi A, Bacsó Z and Scholtz B: miR-126 inhibits proliferation of small cell lung cancer cells by targeting SLC7A5. FEBS Lett 585: 1191-1196, 2011.

28. Feng R, Chen X, Yu Y, Su L, Yu B, Li J, Cai Q, Yan M, Liu B and Zhu Z: miR-126 functions as a tumour suppressor in human gastric cancer. Cancer Lett 298: 50-63, 2010.

29. Liu L, Wang YL and Wang JF: Differential expression of miR-21, miR-126, miR-143, miR-373 in normal cervical tissue, cervical cancer tissue and Hela cell. Sichuan Da Xue Xue Bao Yi Xue Ban 43: 536-539, 2012 (In Chinese).

30. Frampton AE, Krell J, Jacob J, Stebbing J, Castellano L and Jiao LR: Loss of miR-126 is crucial to pancreatic cancer progression. Expert Rev Anticancer Ther 12: 881-884, 2012.

31. Herr D, Sallmann A, Bekes I, Konrad R, Holzheu I, Kreienberg R and Wulff C: VEGF induces ascites in ovarian cancer patients via increasing peritoneal permeability by downregulation of Claudin 5. Gynecol Oncol 127: 210-216, 2012.

32. Kaneko S, Ishibashi M and Kaneko M: Vascular endothelial growth factor expression is closely related to irinotecan-mediated inhibition of tumor growth and angiogenesis in neuroblastoma xenografts. Cancer Sci 99: 1209-1217, 2008.

33. Wang L, Liu X, Wang H and Wang S: Correlation of the expression of vascular endothelial growth factor and its receptors with microvessel density in ovarian cancer. Oncol Lett 6: 175-180, 2013.

34. Cheng D, Liang B and Li Y: Serum vascular endothelial growth factor (VEGF-C) as a diagnostic and prognostic marker in patients with ovarian cancer. PLoS One 8: e55309, 2013.

35. Teng LS, Jin KT, He KF, Zhang J, Wang HH and Cao J: Clinical applications of VEGF-trap (aflibercept) in cancer treatment. J Chin Med Assoc 73: 449-456, 2010.

36. Elice F and Rodeghiero F: Side effects of anti-angiogenic drugs. Thromb Res (Suppl 1): S50-S53, 2012.

37. des Guetz G, Uzzan B, Chouahnia K and Morere JF: Cardiovascular toxicity of anti-angiogenic drugs. Target Oncol 6: 197-202, 2011.

38. Wang F, Ren X and Zhang X: Role of microRNA-150 in solid tumors. Oncol Lett 10: 11-16, 2015.

39. Srinivasan D and Plattner R: Activation of Abl tyrosine kinases promotes invasion of aggressive breast cancer cells. Cancer Res 66: 5648-5655, 2006. 